\title{
Transvaginal urethrolysis for obstruction following anti-incontinence surgery
}

Rebecca McCrery • Rodney Appell

Published online: 14 July 2007

(C) International Urogynecology Journal 2007

The name of the second author was inadvertently omitted from the original publication.

The online version of the original article can be found at http://dx.doi. org/10.1007/s00192-006-0208-5.

R. McCrery $(\bowtie) \cdot$ R. Appell

Scott Department of Urology, Baylor College of Medicine,

6560 Fannin, Suite 2100,

Houston, TX 77030, USA

e-mail: rebeccamccrery@hotmail.com 